FAMILY LEAVE AND DEVELOPMENTAL OUTCOMES

\title{
Paid Maternal Leave is Associated with Better Language and Socioemotional Outcomes During Toddlerhood
}

Karina Kozak $^{1}$, Ashley Greaves ${ }^{1}$, Jane Waldfogel ${ }^{2}$, Jyoti Angal ${ }^{3,4}$, Amy J. Elliott ${ }^{3,4}$, William P. Fifier $^{5,6,7}, \&$ Natalie H. Brito ${ }^{1}$

${ }^{1}$ Department of Applied Psychology, New York University, New York, NY, 10003

${ }^{2}$ School of Social Work, Columbia University, New York, NY, 10027

${ }^{3}$ Center for Pediatric \& Community Research, Avera Research Institute, Sioux Falls, SD 57108

${ }^{4}$ Department of Pediatrics, University of South Dakota School of Medicine, Sioux Falls, SD 57104

${ }^{5}$ Department of Pediatrics, Columbia University Medical Center, New York, NY 10032

${ }^{6}$ Division of Developmental Neuroscience, New York State Psychiatric Institute, New York, NY 10032

${ }^{7}$ Department of Psychiatry, Columbia University Medical Center, New York, NY 10032

Key words: Family leave, socioeconomic status, language, socioemotional development

Corresponding Author:

Natalie Hiromi Brito

New York University

Kimball Hall 407W

246 Greene Street

New York, NY 10003

natalie.brito@nyu.edu 
FAMILY LEAVE AND DEVELOPMENTAL OUTCOMES

\begin{abstract}
The United States is the only high-income country that does not have a national policy mandating paid leave to working women who give birth. Increased rates of maternal employment post-birth call for greater understanding of the effects of family leave on infant development. This study examined the links between paid leave and toddler language, cognitive, and socioemotional outcomes (24-36 months; $\mathrm{N}=446)$. Results indicate that paid leave was associated with better language outcomes, regardless of socioeconomic status. Additionally, paid leave was correlated with fewer infant behavior problems, specifically for mothers on the lower end of the SES spectrum. Expanding access to policies that support families in need, like paid family leave, may aid in reducing socioeconomic disparities in infant development.
\end{abstract}


FAMILY LEAVE AND DEVELOPMENTAL OUTCOMES

\section{INTRODUCTION}

In $2018,61.5 \%$ of mothers in married-couple families and $68.8 \%$ of single-parent mothers with children under the age of 6 were employed (U.S. Department of Labor, Bureau of Labor Statistics, 2019). Being a mother is a lifetime effort, but the period after childbirth might be particularly critical for both mothers and their children. Mothers often deal with a host of perinatal experiences including post-birth complications, sleep disruption, lasting weight fluctuations, lactation difficulties, severe exhaustion, and postpartum depression (Abou-Dakn, Schafer-Graf, \& Wockel, 2009; Saxbe, Rossin-Slater, \& Goldenberg, 2018; Schulte et al., 2017). Nevertheless, an estimated $43 \%$ of first-time mothers returned to their jobs within one month of childbirth (Laughlin, 2011), and about 23\% of women go back to work within two weeks of giving birth (Pozniak et al., 2014). The first few months of life are also a time for infants to develop their foundational cognitive (Fischer, 1980; Burchinal, Roberts, Nabors, \& Bryant, 1996; Davis \& Sandman, 2010), linguistic (Bornstein \& Tamis-Lemonda, 1997; Weisleder \& Fernald, 2013; Friedmann \& Rusou, 2015), and socioemotional (Seifer, Schiller, Sameroff, Resnick, \& Riordan, 1996; Edwards \& Hans, 2015) skills - most optimally achieved within sensitive and responsive interactions with their caregivers (Calkins, 2011; Morris, Silk, Steinberg, Myers, \& Robinson, 2007; Thompson, 1994).

\section{Mother-Infant Interactions Post-Birth}

In the first year of life, infants almost exclusively rely on their parents to co-regulate their arousal, emotion, attention, behavior, and cognition (Calkins, 2011). Calkins (2011) defines selfregulation as the set of biological and behavioral control mechanisms that enable an individual to manage these processes. Without the neurological, psychological, linguistic, and motoric abilities to self-regulate, it is important for newborns and their caregivers to share numerous and repeated 
FAMILY LEAVE AND DEVELOPMENTAL OUTCOMES

experiences, become sensitized to the physiological and behavioral cues from each other, and eventually form a positive and enduring bond. Above providing the basic needs of nutrition, shelter, and cognitive stimulation, these early parent-infant interactions provide the foundation for future positive social interactions and environmental exploration (Feldman, 2003). This foundation is facilitated by dyadic sensitive and responsive practices like gaze, touch, vocalization, and affect (Calkins, 2011) and is found to support children's cognitive and socialemotional development across the first five years of life (Feldman \& Eidelman, 2009a). For example, in one study, 10-month-old infants altered their babbling to mirror the phonological structure of their mother's verbal language only when mothers responded in a temporally contingent manner (Goldstein \& Schwade, 2008). In a similar study, maternal responsive and contingent behaviors were positively associated with infant language outcomes at 21-months (Nicely et al., 1999).

Parent-infant interactions can be adversely affected by caregiver or environmental stress. Stress is typical in the first few months of caregiving, however, in unhealthy amounts, stress can hinder a caregiver's ability to responsively tend to their infant's cues. For example, mothers who report higher levels of stress have been found to exhibit lower levels of sensitivity to infant cues during dyadic interactions (Crnic et al., 1983; Lutz et al., 2013). Similarly, infants of mothers who exhibit higher levels of chronic physiological stress (measured through hair cortisol) have been shown to exhibit alterations in brain function during the first year of life (Troller-Renfree et al., 2019). Given the important contributions of early parental sensitivity on longitudinal child developmental outcomes, these studies point to the necessity of mitigating excess postpartum stress.

\section{Maternal Employment}


FAMILY LEAVE AND DEVELOPMENTAL OUTCOMES

Maternal employment does not prohibit responsive and supportive mother-infant relationships. By nature, employment may decrease the quantity of mother-infant time together (Fox et al., 2013), but not necessarily the quality. For example, Hsin \& Felfe (2014) found that while full-time working mothers spent less total time with their children (ages 0-12), compared to mothers who were unemployed or worked part-time, full-time mothers on average spent a greater proportion of time with their children on educational activities like studying and reading, as well as structured activities like organized sports, arts, and music. Moreover, maternal employment may have many indirect benefits for families. Within a sample of low-income mothers, Coley and colleagues (2007) reported that being employed was associated with decreases in (1) mothers' depressive symptoms, (2) financial strain, and (3) food insecurity most likely due to increases in income and resources.

Rather than simply examining the impact of maternal employment, it may be that the timing of maternal employment plays a larger role in parent-child interactions and subsequent child development. Past studies have reported negative associations between maternal employment and academic achievement during early childhood, even after controlling for various confounds like socioeconomic status (SES) or childcare (Han, Waldfogel, \& BrooksGunn, 2001; Ruhm, 2004; Waldfogel, Han, \& Brooks-Gunn, 2002). Interestingly, these negative associations were specific to maternal employment in the first few months of the infant's life. Maternal employment between 3 to 12 months after childbirth has been linked to higher maternal sensitivity (Brooks-Gunn, Han, \& Waldfogel, 2010; Buehler \& O’Brien, 2011), fewer depressive symptoms (Buehler \& O’Brien, 2011; Mandal, 2018), and higher scores on measures of cognitive stimulation and parent-child interactions within the home (Brooks-Gunn et al., 2010). Furthermore, employment in the second- and third- year of the child's life has been reported to 
FAMILY LEAVE AND DEVELOPMENTAL OUTCOMES

be positively associated with early cognitive outcomes (Waldfogel et al., 2002) and socioemotional development (Han et al., 2001), with some studies reporting outsized benefit for families from lower socioeconomic backgrounds (Bullinger, 2019; Byker, 2016; Rossin-Slater et al., 2013). Given these timing effects of maternal employment, it is important to understand how differences in paid vs. unpaid leave could impact child developmental outcomes.

\section{Maternal Leave Post-Birth}

Despite evidence that mothers may need supported time with their infants after giving birth, U.S. federal policies do not adequately assist working moms. The United States is the only OECD (Organization for Economic Cooperation and Development) country without a national policy of paid maternity leave and currently, only eight U.S. states (California, New Jersey, New York, Rhode Island, Massachusetts, Washington, Oregon, and Connecticut), and the District of Columbia have a paid family leave policy at the state-level. What is in place currently at the federal level is the Family and Medical Leave Act (FMLA), which guarantees up to 12 weeks of unpaid leave to qualifying employees for specified family and medical leave (U.S. Department of Labor, Wage and Hour Division, 2012). Eligibility requires that employees have worked for the same employer for 12 months, have at least 1,250 hours of service during the year preceding the leave, and work at a location where the employer has at least 50 employees within 75 miles of the job's location. Under these guidelines, only half of mothers between 18 and 34 years old are eligible for this benefit (IMPAQ International, 2017; Klerman, Daley, \& Pozniak, 2012). Additionally, unless a company pays for maternity time off or an individual lives in a state that offers wage replacement policies, their leave is likely to be unpaid; consequently, it is less likely to be used as parents are unable to sacrifice their income in order to stay at home with their young infants (Stearns, 2015). Research has shown, however, that offering paid leave increases 
FAMILY LEAVE AND DEVELOPMENTAL OUTCOMES

the odds of families staying at home with their infants. California's Paid Family Leave Program increased maternal leave claims from $36.4 \%$ of new mothers in 2004 , when the program started, to $45.5 \%$ in 2014 (Rossin-Slater, 2018). This program also doubled the overall length of maternity leave taken, from 3 to 6 weeks, with higher rates within socioeconomically disadvantaged groups (Rossin-Slater, Ruhm, \& Waldfogel, 2013).

The availability of paid leave at the state level has already begun to show positive health repercussions. In California, mothers demonstrated significant increases in breastfeeding after the passage of paid leave compared to mothers of similar demographic backgrounds in other states (Huang \& Yang, 2015). Using a national sample, researchers found that returning to work within 12 weeks of childbirth was associated with higher maternal depression scores, but mothers who received paid leave on average had lower depression scores (Mandal, 2018). Using the policy change in California as a natural experiment, Bullinger (2019) found improvements in parent-reported child health and maternal mental health, as well as higher ratings in parent's ability to cope with the daily demands of parenting. Overall, protected paid leave may offer a period of time for mothers to recover from the numerous stressors of childbirth and postpartum care, as well as acclimate to the responsibilities of parenthood without risk of financial loss and increased stress.

\section{Current Study}

The literature suggests that both infants and mothers benefit from some paid, jobprotected time at home after childbirth, as it may increase the likelihood and length of maternal leave to foster sensitive, reciprocal parent-child interactions in the first year of life (RossinSlater, Ruhm, \& Waldfogel, 2013; Rossin-Slater, 2018), as well as reduce financial stress that may dampen these experiences (McKelvey, Fitzgerald, Schiffman, \& Von Eye, 2002). Most of 
FAMILY LEAVE AND DEVELOPMENTAL OUTCOMES

the studies in the United States thus far have examined the effects of family leave on maternal mental wellbeing or child health. Very little is known about the potential links between paid vs. unpaid maternal leave and children's subsequent cognitive development. First, compared to mothers who do not return to work, we hypothesize that mothers who return to work at some point after giving birth will have toddlers with higher developmental outcomes. We further hypothesize that mothers who receive a paid leave post-birth will have toddlers who demonstrate higher cognitive, linguistic, and socio-emotional outcomes. To be more specific, we hypothesize that independent of SES, post-birth paid leave will be positively associated with toddler developmental outcomes. Third, these associations will be strongest for families from lower SES households who may face the most stress from an unpaid leave. Finally, longer durations of paid leave in the first year of life will be positively associated with toddler outcomes.

\section{METHODS}

\section{Participants}

The current sample included 446 children (227 males; age $M=29.53$ months, $S D=4.28$ ) who were recruited from a larger sample of families who had previously participated in a neonatal study. Participants were excluded from participating in the present study on the basis of birth before 30 weeks' gestation, multiple births, or NICU admission. At the time of data collection, FMLA was available to all eligible families, but families did not live in states that had paid leave policies in place. The racial breakdown of this sample was as follows: $62 \%$ White, 13\% Bi-racial, 9\% American Indian or Alaskan Native, 7\% Asian, 3\% Black, and 6\% unreported. All caregivers provided informed consent for their family's participation in this study and research procedures were approved by the Columbia University Medical Center and Sanford Health IRBs. 
FAMILY LEAVE AND DEVELOPMENTAL OUTCOMES

\section{Measures}

Family and Household Characteristics. Mothers were given a questionnaire in which they reported on their socioeconomic status (highest level of education attained, annual household income), employment experiences (working or unemployed) and their infant's age and gestational age at birth. If mothers reported working during pregnancy they were asked: (1) if they took time off after giving birth, (2) if this time off was compensated monetarily in any way, and (3) how long they took off before returning to work. If mothers reported any monetary compensation during their leave, they were categorized as having paid leave.

Developmental Assessments at 24-36 Months. To maximize the number of participants, parental self-report measures were used rather than observer-rated measures, as many families had moved out of the immediate area and were unable to return for a lab visit. Assessments were given over the phone by trained research assistants and took 45 to 60 minutes to complete.

The Brief Infant Toddler Social Emotional Assessment (BITSEA). The BITSEA is a tool to evaluate potential risk for social and emotional developmental problems or delays in social competence amongst children 12 to 36 months of age (Briggs-Gowan \& Carter, 2007; Briggs-Gowan, Carter, Irwin, Wachtel, \& Cicchetti, 2002; Briggs-Gowan, Carter, Irwin, Wachtel, \& Cicchetti, 2004; Briggs-Gowan et al, 2013). The assessment contains 42 questions, each requiring one of three responses: true/rarely, somewhat true/sometimes, or very true/often. The assessment yields two scores related to behavior problems (e.g., is restless and can't sit still, has trouble adjusting to changes) and social competence (e.g., "plays well with other children, points to show you something far away). Past studies have reported significant correlations between this parental-report measure of socioemotional ability and experimenter conducted assessment measures like the Infant Mullen Scales of Early Learning and the Vineland Adaptive 
FAMILY LEAVE AND DEVELOPMENTAL OUTCOMES

Behavior Scales for Children (Briggs-Gowan \& Carter, 2008). Additionally, the BITSEA has been validated relative to a clinical diagnostic interview (sensitivity: $73 \%-81 \%$; specificity: $70 \%$ 83\%) and the commonly used Child Behavior Checklist (CBCL) (sensitivity: 80\%-96\%; specificity: 75\%-90\%) (Briggs-Gowan et al., 2013).

The Parent Report of Children's Abilities-Revised (PARCA-R). The PARCA-R is a parent-report assessment for examining potential risk for linguistic and cognitive delays in toddlers (Blaggan et al., 2014) and has been used in large-scale national studies (Johnson et al., 2015; Saudino et al., 1998). PARCA-R has been validated against the Bayley Scales of Infant Development III (BSID III), with Spearman rank-order correlations between the parent-report PARCA-R measure and BSID III experimenter elicited measure of 0.43 for cognitive sections and 0.71 for language sections (Martin et al, 2013). Sections of the report include nonverbal cognition (34 questions), vocabulary (list of 100 common words), and sentence complexity (12 questions). The vocabulary and sentence complexity scores were summed to create the linguistic score.

\section{RESULTS}

All participants were categorized into groups based on maternal employment and leave status: (1) mothers who did not work before giving birth and continued not to work after giving birth [Not Working], (2) mothers who previously worked but did not return to work after giving birth [Stopped Working After Birth], (3) mothers who took unpaid leave before returning to work [Working - Unpaid Leave], and (4) mothers who took paid leave before returning to work [Working - Paid Leave]. See Table 1 for demographic information for each category.

Within subsequent analyses, gestational age at birth, infant sex, family income, and maternal education were included as covariates in all subsequent analyses as these variables have 
FAMILY LEAVE AND DEVELOPMENTAL OUTCOMES

been previously found to impact early cognitive, linguistic, and behavioral development (Bradley \& Corwyn, 2002; Foster-Cohen, Edgin, Champion, \& Woodward, 2007; Noble et al., 2012;

Noble et al., 2015; McCarton, Wallace, Divon, \& Vaughan, 1996; Prior, Smart, Sanson, \& Oberklaid, 1993; Schirmer, Portuguez, \& Nunes, 2006). Site was also included as a covariate in all paid vs. unpaid leave analyses, in addition to the other covariates, to control for any unmeasured differences between the two samples. The child outcome measures fell into three categories: socioemotional (BITSEA problem and social competence score), language (PARCA$\mathrm{R}$ linguistic score,) and cognitive (PARCA-R cognitive score).

\section{Socioeconomic Status and Developmental Outcomes}

This sample had high variability in income (Range $=\$ 3 \mathrm{~K}$ to $\$ 100 \mathrm{~K}+$ ) and maternal education (Range $=6$ to 25 years). This variability existed within the four different maternal employment categories, see Figure 1._Multiple linear regressions were conducted to examine the impact of both income and maternal education on child outcomes. When controlling for covariates, higher income was associated with lower BITSEA problem scores $(\beta<-.01, p=$ $<.01$, adj. $\left.\mathrm{R}^{2}=.06\right)$, higher BITSEA competence scores $\left(\beta=<.01, p=<.01\right.$, adj. $\left.\mathrm{R}^{2}=.07\right)$, higher PARCA-R cognitive $\left(\beta=<.01, p=<.01\right.$, adj. $\left.\mathrm{R}^{2}=.09\right)$, and linguistic scores $(\beta=<.01, p=<.01$, adj. $\left.\mathrm{R}^{2}=.24\right)$. Controlling for the same covariates, more years of maternal education was associated with lower problem scores $\left(\beta=-.44, p=<.01\right.$, adj. $\left.\mathrm{R}^{2}=.04\right)$, higher BITSEA competence scores $\left(\beta=.09, p=.04, a d j . \mathrm{R}^{2}=.05\right)$, higher PARCA-R cognitive $(\beta=.22, p=$ $<.01$, adj. $\left.\mathrm{R}^{2}=.08\right)$, and linguistic scores $\left(\beta=2.18, p=<.01\right.$, adj. $\left.\mathrm{R}^{2}=.21\right)$.

\section{Maternal Employment and Developmental Outcomes}

The associations of maternal employment with developmental outcomes were examined with family income and maternal education included as additional covariates. Mothers that 
FAMILY LEAVE AND DEVELOPMENTAL OUTCOMES

returned to work after giving birth and taking some time off had infants who had higher linguistic scores during toddlerhood $\left(\beta=7.73, p=0.02\right.$, adj. $\mathrm{R}^{2}=0.24$; Table 3$)$ than mothers that did not return to work or had not been working before the baby was born (Figure 2). To ensure that this effect was not attributable to income, the sample was divided into two groups based on income using a median split. Associations between maternal employment and linguistic scores were present for both lower and higher income groups. No other significant associations were found for any other outcome of interest ( $p$ 's $>0.17)$.

\section{Paid Leave is Associated with Higher Language and Socioemotional Scores}

In order to examine the effects of paid versus unpaid leave on child outcomes, multiple linear regressions were conducted for each child outcome measure. Examining the effect of paid versus unpaid leave on child outcomes, mothers who had paid leave after childbirth had toddlers with significantly higher linguistic scores than children of mothers with unpaid leave after birth $\left(\beta=8.96, p=0.01, a d j . \mathrm{R}^{2}=0.19 ;\right.$ Table 4, Figure 3). In an effort to disentangle SES from experiences of paid leave, we also examined these associations within separate groups of mothers by income levels. Even though income was controlled for within this analysis, it may be that this association is explained by higher family income within the paid leave group. To ensure this was not the case, the sample was divided into two groups based on the median split of income and the same regression was rerun within each income group. Results indicated a significant association between type of leave and linguistic scores for both income groups, indicating that the link between paid leave and higher linguistic scores was still present for the lower income group. There were no significant differences between toddlers whose mothers took paid versus unpaid leave on cognitive or socioemotional scores ( $p$ 's $>0.54)$. 
FAMILY LEAVE AND DEVELOPMENTAL OUTCOMES

The amount of stress caused by a reduction in income due to unpaid family leave may have a disproportionate effect on families on the lower end of the socioeconomic spectrum. In the next set of analyses, we examine the possible moderating role of SES on the relation between type of leave and toddler developmental outcomes. To examine if SES (maternal education or family income) moderated links between paid leave and developmental outcomes, separate interaction terms (leave * SES) were added to regression models. Results indicated two main effects: (1) toddlers whose mothers had paid leave had significantly lower BITSEA problem scores $\left(\beta=-9.56, p=0.02\right.$, adj. $\left.\mathrm{R}^{2}=0.06\right)$ and (2) higher maternal education was also associated with lower BITSEA problem scores $\left(\beta=-0.45, p=0.04\right.$, adj. $\left.\mathrm{R}^{2}=0.06\right)$. But these results were explained by the interaction between these two variables, as the effect of paid versus unpaid family leave on socioemotional scores was dependent on maternal education $(\beta=0.63, p=0.02$, adj. $\mathrm{R}^{2}=0.06$, Table 4). Probing this interaction, a Johnson-Neyman analysis revealed that this association was only significant at the lower end of the maternal education spectrum (Figure 4). In other words, compared to unpaid leave, paid leave was significantly associated with lower BITSEA problem scores, but this relation was only present for mothers with lower levels of education. There were no significant interactions between type of leave and household income ( $p$ $=0.60)$.

\section{Effect of Length of Leave on Developmental Outcomes}

Finally, to investigate whether the length of maternal leave was associated with child outcomes, the time in weeks that mothers took off after giving birth was included as a predictor variable. There were no significant differences in length of leave between the unpaid ( $M=13.16$ weeks, $\mathrm{SD}=9.90$, range $=1-48$ weeks $)$ and paid leave $(M=11.65, \mathrm{SD}=4.66$, range $=2-36$ weeks) groups $(p=0.12)$. Length of leave was also not related to maternal education $(p=0.68)$ 
FAMILY LEAVE AND DEVELOPMENTAL OUTCOMES

or household income $(p=0.23)$. To examine if the duration of time at home with the infant could explain differences in type of leave and developmental outcomes, both length of paid leave and length of unpaid leave were analyzed separately as predictor variables. For both groups, the length of leave did not have a significant effect on any of the outcome variables ( $p$ 's $>0.26)$, see Figure 5.

\section{DISCUSSION}

This is the first U.S. study, to our knowledge, to examine the association between paid leave and early child cognitive, linguistic, and socioemotional outcomes. The sample in the current study was not only diverse in terms of SES, but there was also high variation in terms of who had access to paid and unpaid leave. This unique combination enabled us to examine the effects of paid leave in various socioeconomic contexts.

Like past studies (Brooks-Gunn et al., 2010; Laing \& Bergelson, 2018), our results suggest that maternal employment can have a beneficial effect on child cognitive outcomes. Both for the entire sample and for women from lower-income households, mothers that returned to work had infants that scored significantly higher on language scores. While this might be surprising, given that working mothers likely spend less total time interacting with their infants, three other factors might explain this result. First, it is possible that the child benefits from having many different adults to interact with, broadening the infant's linguistic inputs. Experiencing one-on-one interactions with many adults, including primary, babysitters and daycare workers, each with their own vocabulary and way of speaking, may enrich an infant's linguistic environment (Golinkoff, Can, Soderstrom, \& Hirsh-Pasek, 2015). Second, as Hsin and Felfe (2014) suggest, it might be possible that the working mothers in this sample were more intentional with the limited time they did spend with their infants and may have attempted to 
FAMILY LEAVE AND DEVELOPMENTAL OUTCOMES

maximize the quality of those interactions. A third possible explanation is that it may be beneficial for maternal mental health to spend time outside of the home, as caring for young children can be highly stressful and exhausting; better mental health could, in turn, positively influence parent-child language interactions. While this is purely speculation, it is supported by Mandal (2018), who found fewer depressive symptoms among mothers that returned to work during infancy after the first 12 weeks post-birth and by studies indicating links between maternal depressive symptoms and early language development (Sohr-Preston \& Scaramella, 2006).

The positive effects of maternal employment on child language and cognitive outcomes cannot be explained merely by income. In an effort to disentangle any SES effects from the relationship with family leave, we both controlled for income within our statistical analyses and we also examined associations between family leave and cognitive outcomes within a subsample of lower-income mothers. In both instances maternal employment was positively associated with child cognitive outcomes. More research on maternal employment decision making and childcare quality in conjunction with cognitive outcomes needs to be conducted to better understand underlying mechanisms.

With regards to our second research question, results indicated that mothers who received compensation in some way during their time off after childbirth had toddlers with significantly higher language scores. A potential mechanism for this result may be reduced maternal stress. The birth of a child incurs new expenses for a family and having to take time off from work without pay puts an additional financial strain on an already stressful situation. Prior studies have reported links between higher maternal stress and lower maternal sensitivity and responsiveness (Crnic, Greenberg, Robinson, \& Ragozin, 1984; Feldman, Eidelman, \& Rotenberg, 2004). It may 
FAMILY LEAVE AND DEVELOPMENTAL OUTCOMES

be that, compared to mothers who take paid leave, mothers with unpaid leave experience more financial-related stress, potentially leading to fewer sensitive and responsive interactions with their infants and subsequent differences in toddler language abilities. Future studies should include measures of maternal stress (both physiological and perceived) to include as a possible mediator between the type of leave and child language outcomes.

It is reasonable to imagine that paid leave would be especially beneficial to mothers living in lower SES households as a lack of income after childbirth would exacerbate their financial stress exponentially more than mothers with financial security. When examining the interactive effect of SES on the link between paid leave and socioemotional outcomes, we find that the association between paid leave and lower BITSEA problem scores was only significant for mothers whose highest level of educational attainment was a high school degree or less. Our results suggest that paid leave may have an outsized benefit to mothers on the lower-end of the socioeconomic spectrum, replicating past findings (Bullinger, 2019, Byker, 2016 and RossinSlater et al., 2013). While mothers from higher SES households are more likely to have access to paid leave, as our study shows, there are situations in which mothers from lower SES households may also receive some paid time off after giving birth. Mothers could be eligible for some paid leave if they work for a large company, like a university or bank, that extends this benefit to all employees. Mothers may also be able to use their accrued vacation or sick days to cover their paid time off. In an effort to disentangle SES effects from associations with paid leave, and to ensure our results were not solely due to selection bias, we re-ran all analyses with only families from lower-SES households and still found the same results demonstrating the benefits of paid leave. This further supports the idea that, though mothers from lower SES households may have 
FAMILY LEAVE AND DEVELOPMENTAL OUTCOMES

less access to paid family leave, when they do have it, it is associated with positive language and socioemotional outcomes for their children.

Contrary to previous work, the current analysis did not find a link between length of leave and developmental outcomes during toddlerhood. This was somewhat surprising given the assumption that if time off is beneficial for mothers, we might expect there to be either a positive correlation with the length of time off or an optimal amount of time off. It is possible that too much or too little time off is associated with negative outcomes, indicative of a U-shaped curve, but we could not determine this from our dataset. One explanation may be that in our sample very few mothers took less than 2 weeks or more than 12 weeks off after childbirth (paid or unpaid). Therefore, our sample did not have enough extreme cases to adequately investigate the effects of length of leave.

There are many limitations in this current study. First, aside from basic questions about employment and time off after childbirth, we do not have a full picture of the family's employment situation. For example, we do not have information about how mothers had access to paid leave (e.g., whether it was part of company policy, if they used vacation days, how much it covered, etc.), or whether a second caregiver received paid leave. A more comprehensive questionnaire or qualitative interview should be used in the future to address these nuances. Second, while the BITSEA and PARCA-R surveys are widely used, it is a limitation that our study does not include any experimenter administered assessments. Although past studies have reported on the validity of the specific parent-report assessments used within this study in relation to laboratory-based measures (Johnson, Wolke, Marlow, 2008; Martin et al., 2013), it is possible that parent's perceptions of their child's skills and abilities could also be impacted by environments of stress, directly or indirectly related to post-birth experiences. The current 
FAMILY LEAVE AND DEVELOPMENTAL OUTCOMES

preliminary findings would benefit from replication with other measures of cognitive development like experimenter elicited behavioral assessments and neurophysiological measurements. Additionally, while we speculated that maternal stress may be a mechanism that explains these differences, future studies should include measures of maternal stress (both physiological and perceived) to include as a possible mediator between the type of leave and child outcomes.

There are many pathways through which early life stress and adversity can lead to differences in neurocognitive outcomes for young children (Brito \& Noble, 2014). In addition to adequate prenatal care and household resources, sufficient quality time between mother and infant, as well as time to adjust to the newfound stressors of parenthood, may be crucial to the mental health of the mother and subsequent development of the child. Public policies like mandated paid family leave would support all families during this sensitive period of infant development, but its positive effects could specifically target and benefit the most economically disadvantaged families - possibly alleviating disparities in infant outcomes. 
FAMILY LEAVE AND DEVELOPMENTAL OUTCOMES

\section{References}

Abou-Dakn, M., Schäfer-Graf, U., \& Wöckel, A. (2009). Psychological stress and breast diseases during lactation. Breastfeeding Review: Professional Publication of the Nursing Mothers' Association of Australia, 17(3), 19-26.

Blaggan, S., Guy, A., Boyle, E. M., Spata, E., Manktelow, B. N., Wolke, D., \& Johnson, S. (2014). A parent questionnaire for developmental screening in infants born late and moderately preterm. Pediatrics, 134(1), e55-e62.

Bornstein, M. H., \& Tamis-Lemonda, C. S. (1997). Maternal responsiveness and infant mental abilities: Specific predictive relations. In Infant Behavior and Development (Vol. 20, Issue 3, pp. 283-296). https://doi.org/10.1016/s0163-6383(97)90001-1

Bradley, R. H., \& Corwyn, R. F. (2002). Socioeconomic status and child development. Annual Review of Psychology, 53, 371-399.

Briggs-Gowan, M. J. (2004). The Brief Infant-Toddler Social and Emotional Assessment: Screening for Social-Emotional Problems and Delays in Competence. Journal of Pediatric Psychology, 29(2), 143-155.

Briggs-Gowan, M. J., \& Carter, A. S. (2008). Social-Emotional Screening Status in Early Childhood Predicts Elementary School Outcomes. In PEDIATRICS (Vol. 121, Issue 5, pp. 957-962). https://doi.org/10.1542/peds.2007-1948

Briggs-Gowan, M. J., Carter, A. S., Irwin, J. R., Wachtel, K., \& Cicchetti, D. V. (2002). Brief Infant-Toddler Social and Emotional Assessment (BITSEA) manual, version 2.0. New Haven, CT:Yale University

Briggs-Gowan, M. J., Irwin J.R., Wachtel K., Cicchetti D.V., Carter, A. S. (2007). Applying the Infant-Toddler Social \& Emotional Assessment (ITSEA) and Brief-ITSEA in early 
FAMILY LEAVE AND DEVELOPMENTAL OUTCOMES

intervention. Infant Mental Health Journal, 28(6), 564-583.

Briggs-Gowan, M. J., Carter, A. S., McCarthy, K., Augustyn, M., Caronna, E., \& Clark, R. (2013). Clinical Validity of a Brief Measure of Early Childhood SocialEmotional/Behavioral Problems. In Journal of Pediatric Psychology (Vol. 38, Issue 5, pp. 577-587). https://doi.org/10.1093/jpepsy/jst014

Brito, N. H., \& Noble, K. G. (2014). Socioeconomic status and structural brain development. Frontiers in Neuroscience, 8, 276.

Brooks-Gunn, J., Han, W.-J., \& Waldfogel, J. (2010). First-Year Maternal Employment and Child Development in the First 7 Years. Wiley-Blackwell.

Buehler, C., \& O’Brien, M. (2011). Mothers' part-time employment: Associations with mother and family well-being. In Journal of Family Psychology (Vol. 25, Issue 6, pp. 895-906). https://doi.org/10.1037/a0025993

Bullinger, L. R. (2019). The Effect of Paid Family Leave on Infant and Parental Health in the United States. Journal of Health Economics, 66, 101-116.

Burchinal, M. R., Roberts, J. E., Nabors, L. A., \& Bryant, D. M. (1996). Quality of center child care and infant cognitive and language development. Child Development, 67(2), 606-620.

Byker, T. S. (2016). Paid Parental Leave Laws in the United States: Does Short-Duration Leave Affect Women's Labor-Force Attachment? In American Economic Review (Vol. 106, Issue 5, pp. 242-246). https://doi.org/10.1257/aer.p20161118

Calkins, S. D. (2011). Caregiving as Coregulation: Psychobiological Processes and Child Functioning. In National Symposium on Family Issues (pp. 49-59). https://doi.org/10.1007/978-1-4419-7361-0_3

Coley, R. L., Lohman, B. J., Votruba-Drzal, E., Pittman, L. D., \& Chase-Lansdale, P. L. (2007). 
FAMILY LEAVE AND DEVELOPMENTAL OUTCOMES

Maternal functioning, time, and money: The world of work and welfare. Children and Youth Services Review, 29(6), 721-741.

Crnic, K. A., Greenberg, M. T., Ragozin, A. S., Robinson, N. M., \& Basham, R. B. (1983). Effects of stress and social support on mothers and premature and full-term infants. Child Development, 54(1), 209-217.

Davis, E. P., \& Sandman, C. A. (2010). The timing of prenatal exposure to maternal cortisol and psychosocial stress is associated with human infant cognitive development. Child Development, 81(1), 131-148.

Edwards, R. C., \& Hans, S. L. (2015). Infant risk factors associated with internalizing, externalizing, and co-occurring behavior problems in young children. In Developmental Psychology (Vol. 51, Issue 4, pp. 489-499). https://doi.org/10.1037/a0038800

Feldman, R. (2003). Infant-mother and infant-father synchrony: The coregulation of positive arousal. In Infant Mental Health Journal (Vol. 24, Issue 1, pp. 1-23). https://doi.org/10.1002/imhj.10041

Feldman, R., \& Eidelman, A. I. (2009). Triplets across the first 5 years: the discordant infant at birth remains at developmental risk. Pediatrics, 124(1), 316-323.

Feldman, R., Eidelman, A. I., \& Rotenberg, N. (2004). Parenting stress, infant emotion regulation, maternal sensitivity, and the cognitive development of triplets: a model for parent and child influences in a unique ecology. Child Development, 75(6), 1774-1791.

Fischer, K. W. (1980). A theory of cognitive development: The control and construction of hierarchies of skills. In Psychological Review (Vol. 87, Issue 6, pp. 477-531). https://doi.org/10.1037/0033-295x.87.6.477

Foster-Cohen, S., Edgin, J. O., Champion, P. R., \& Woodward, L. J. (2007). Early delayed 
FAMILY LEAVE AND DEVELOPMENTAL OUTCOMES

language development in very preterm infants: evidence from the MacArthur-Bates CDI. Journal of Child Language, 34(3), 655-675.

Fox, L., Han, W.-J., Ruhm, C., \& Waldfogel, J. (2013). Time for children: trends in the employment patterns of parents, 1967-2009. Demography, 50(1), 25-49.

Friedmann, N., \& Rusou, D. (2015). Critical period for first language: the crucial role of language input during the first year of life. Current Opinion in Neurobiology, 35, 27-34.

Goldstein, M. H., \& Schwade, J. A. (2008). Social feedback to infants' babbling facilitates rapid phonological learning. Psychological Science, 19(5), 515-523.

Han, W.-J., Waldfogel, J., \& Brooks-Gunn, J. (2001). The Effects of Early Maternal Employment on Later Cognitive and Behavioral Outcomes. In Journal of Marriage and Family (Vol. 63, Issue 2, pp. 336-354). https://doi.org/10.1111/j.1741-3737.2001.00336.x Hsin, A., \& Felfe, C. (2014). When Does Time Matter? Maternal Employment, Children's Time with Parents, and Child Development. Demography, 51(5), 1867-1894.

Huang, R., \& Yang, M. (2015). Paid maternity leave and breastfeeding practice before and after California's implementation of the nation's first paid family leave program. In Economics \& Human Biology (Vol. 16, pp. 45-59). https://doi.org/10.1016/j.ehb.2013.12.009

IMPAQ International LLC. (2017). Qualifying for Unpaid Leave: FMLA Eligibility among Working Mothers. Institute for Women's Policy Research Issue Brief. Retrieved from https://www.dol.gov/sites/dolgov/files/OASP/legacy/files/IMPAQ-Working-Mothers.pdf

Johnson, S., Evans, T. A., Draper, E. S., Field, D. J., Manktelow, B. N., Marlow, N., Matthews, R., Petrou, S., Seaton, S. E., Smith, L. K., \& Boyle, E. M. (2015). Neurodevelopmental outcomes following late and moderate prematurity: a population-based cohort study. Archives of Disease in Childhood. Fetal and Neonatal Edition, 100(4), F301-F308. 
FAMILY LEAVE AND DEVELOPMENTAL OUTCOMES

Johnson, S., Wolke, D., Marlow, N., \& Preterm Infant Parenting Study Group. (2008).

Developmental assessment of preterm infants at 2 years: validity of parent reports. Developmental Medicine \& Child Neurology, 50(1), 58-62.

Klerman, J.A., Daley, K., \& Pozniak, A. (2012). Family and medical leave in 2012: Technical report. Cambridge, MA: Abt Associates. Retrieved from: https://www.dol.gov/asp/evaluation/fmla/fmla-2012-technical-report.pdf

Laughlin, L. (2011). Maternity leave and employment patterns: 2006-2008. Current Population Report P70-128. Washington, DC: U.S. Census Bureau.

Lutz, K. F., Burnson, C., Hane, A., Samuelson, A., Maleck, S., \& Poehlmann, J. (2012).

Parenting Stress, Social Support, and Mother-Child Interactions in Families of Multiple and Singleton Preterm Toddlers. Family Relations, 61(4), 642-656.

Mandal, B. (2018). The Effect of Paid Leave on Maternal Mental Health. Maternal and Child Health Journal, 22(10), 1470-1476.

Martin, A. J., Darlow, B. A., Salt, A., Hague, W., Sebastian, L., McNeill, N., \& Tarnow-Mordi, W. (2013). Performance of the Parent Report of Children's Abilities-Revised (PARCA-R) versus the Bayley Scales of Infant Development III. In Archives of Disease in Childhood (Vol. 98, Issue 12, pp. 955-958). https://doi.org/10.1136/archdischild-2012-303288

McCarton, C. M., Wallace, I. F., Divon, M., \& Vaughan, H. G., Jr. (1996). Cognitive and neurologic development of the premature, small for gestational age infant through age 6: comparison by birth weight and gestational age. Pediatrics, 98(6 Pt 1), 1167-1178.

McKelvey, L. M., Fitzgerald, H. E., Schiffman, R. F., \& Von Eye, A. (2002). Family stress and parent-infant interaction: The mediating role of coping. In Infant Mental Health Journal (Vol. 23, Issues 1-2, pp. 164-181). https://doi.org/10.1002/imhj.10010 
FAMILY LEAVE AND DEVELOPMENTAL OUTCOMES

Morris, A. S., Silk, J. S., Steinberg, L., Myers, S. S., \& Robinson, L. R. (2007). The Role of the Family Context in the Development of Emotion Regulation. In Social Development (Vol. 16, Issue 2, pp. 361-388). https://doi.org/10.1111/j.1467-9507.2007.00389.x

Nicely, P., Tamis-LeMonda, C. S., \& Bornstein, M. H. (1999). Mothers' attuned responses to infant affect expressivity promote earlier achievement of language milestones. In Infant Behavior and Development (Vol. 22, Issue 4, pp. 557-568). https://doi.org/10.1016/s01636383(00)00023-0

Noble, K. G., Engelhardt, L. E., Brito, N. H., Mack, L. J., Nail, E. J., Angal, J., Barr, R., Fifer, W. P., Elliott, A. J., \& in collaboration with the PASS Network. (2015). Socioeconomic disparities in neurocognitive development in the first two years of life. In Developmental Psychobiology (Vol. 57, Issue 5, pp. 535-551). https://doi.org/10.1002/dev.21303

Noble, K. G., Fifer, W. P., Rauh, V. A., Nomura, Y., \& Andrews, H. F. (2012). Academic achievement varies with gestational age among children born at term. Pediatrics, 130(2), e257-e264.

Pozniak, A., Wen, K., Olson, K., Daley, K., \& Klerman, J. (2014). Family and Medical Leave in 2012: Detailed Results Appendix. Abt Associates. Retrieved from https://www.dol.gov/sites/dolgov/files/OASP/legacy/files/FMLA-2012-TechnicalReport.pdf

Prior, M., Smart, D., Sanson, A., \& Oberklaid, F. (1993). Sex differences in psychological adjustment from infancy to 8 years. Journal of the American Academy of Child and Adolescent Psychiatry, 32(2), 291-304; discussion 305.

Rossin-Slater, M. (2018). Maternity and family leave policy. In S.L. Averett, L.M. Argys, \& S.D. Hoffman (Eds.), Oxford handbook of women and the economy. New York, NY: 
FAMILY LEAVE AND DEVELOPMENTAL OUTCOMES

Oxford University Press.

Rossin-Slater, M., Ruhm, C. J., \& Waldfogel, J. (2013). The Effects of California's Paid Family Leave Program on Mothers' Leave-Taking and Subsequent Labor Market Outcomes. In Journal of Policy Analysis and Management (Vol. 32, Issue 2, pp. 224-245). https://doi.org/10.1002/pam.21676

Ruhm, C. J. (2004). Parental Employment and Child Cognitive Development. In The Journal of Human Resources (Vol. 39, Issue 1, p. 155). https://doi.org/10.2307/3559009

Saudino, K. J., Dale, P. S., Oliver, B., Petrill, S. A., Richardson, V., Rutter, M., Simonoff, E., Stevenson, J., \& Plomin, R. (1998). The validity of parent-based assessment of the cognitive abilities of 2-year-olds. In British Journal of Developmental Psychology (Vol. 16, Issue 3, pp. 349-362). https://doi.org/10.1111/j.2044-835x.1998.tb00757.x

Saxbe, D., Rossin-Slater, M., \& Goldenberg, D. (2018). The transition to parenthood as a critical window for adult health. The American Psychologist, 73(9), 1190-1200.

Schirmer, C. R., Portuguez, M. W., \& Nunes, M. L. (2006). Clinical assessment of language development in children at age 3 years that were born preterm. Arquivos de NeuroPsiquiatria, 64(4), 926-931.

Schulte, B., Durana, L., Stout, B., \& Moyer, J. (2017). Paid Family Leave: How Much Time is Enough?. Better Life Lab Report. Retrieved from https://www.newamerica.org/betterlife-lab/reports/paid-family-leave-how-much-time-enough/

Seifer, R., Schiller, M., Sameroff, A. J., Resnick, S., \& Riordan, K. (1996). Attachment, maternal sensitivity, and infant temperament during the first year of life. In Developmental Psychology (Vol. 32, Issue 1, pp. 12-25). https://doi.org/10.1037/0012-1649.32.1.12

Stearns, J. (2015). The effects of paid maternity leave: Evidence from Temporary Disability 
FAMILY LEAVE AND DEVELOPMENTAL OUTCOMES

Insurance. Journal of Health Economics, 43, 85-102.

Thompson, R. A. (1994). EMOTION REGULATION: A THEME IN SEARCH OF

DEFINITION. In Monographs of the Society for Research in Child Development (Vol. 59, Issues 2-3, pp. 25-52). https://doi.org/10.1111/j.1540-5834.1994.tb01276.x

Troller-Renfree, S. V., Brito, N. H., Desai, P. M., Leon-Santos, A. G., Wiltshire, C. A., Motton, S. N., Meyer, J. S., Isler, J., Fifer, W. P., \& Noble, K. G. (2020). Infants of mothers with higher physiological stress show alterations in brain function. In Developmental Science. https://doi.org/10.1111/desc. 12976

U.S. Department of Labor, Bureau of Labor Statistics. (2019, January). Monthly Labor Review: Racial and ethnic disparities in access to and use of paid family and medical leave: evidence from four nationally representative datasets. Retrieved from https://www.bls.gov/opub/mlr/2019/article/racial-and-ethnic-disparities-in-access-to-and Use-of-paid-family-and-medical-leave.htm

U.S. Department of Labor, Wage and Hour Division. (2012). Fact Sheet \#28: The Family and Medical Leave Act. Retrieved from https://www.dol.gov/whd/regs/compliance/whdfs28.pdf

Waldfogel, J., Han, W.-J., \& Brooks-Gunn, J. (2002). The effects of early maternal employment on child cognitive development. Demography, 39(2), 369-392.

Weisleder, A., \& Fernald, A. (2013). Talking to Children Matters. In Psychological Science (Vol. 24, Issue 11, pp. 2143-2152). https://doi.org/10.1177/0956797613488145 
FAMILY LEAVE AND DEVELOPMENTAL OUTCOMES

\section{Tables}

Table 1.

Demographics

\begin{tabular}{clcc}
\hline Maternal Employment & & Mean & SD \\
\hline \multirow{2}{*}{ 1. Not Working (n=72) } & Gestational Age at Birth & 38.3 weeks & 2.14 \\
& Infant Age & 29.1 months & 4.27 \\
& Maternal Education & 13.3 years & 2.86 \\
& Annual Family Income & $\$ 29,000$ & 23,038 \\
\hline \multirow{2}{*}{$\begin{array}{c}\text { 2. Stopped Working After } \\
\text { Birth (n=46) }\end{array}$} & Gestational Age at Birth & 39.2 weeks & 1.23 \\
& Infant Age & 29.2 months & 4.35 \\
& Maternal Education & 13.6 years & 2.98 \\
& Annual Family Income & $\$ 42,349$ & 28,044 \\
\hline \multirow{2}{*}{$\begin{array}{c}\text { 3. Working - Unpaid Leave } \\
\text { (n=117) }\end{array}$} & Gestational Age at Birth & 38.9 weeks & 1.7 \\
& Infant Age & 30.5 months & 4.35 \\
& Maternal Education & 14.8 years & 2.33 \\
& Annual Family Income & $\$ 37,676$ & 21,881 \\
\hline & Gestational Age at Birth & 38.9 weeks & 1.61 \\
& Infant Age & 29.2 months & 4.17 \\
& Maternal Education & 16.0 years & 2.13 \\
& Annual Family Income & $\$ 54,313$ & 23,342 \\
\hline $\begin{array}{c}\text { 4. Working - Paid Leave } \\
\text { (n=211) }\end{array}$ & &
\end{tabular}


FAMILY LEAVE AND DEVELOPMENTAL OUTCOMES

Table 2.

Toddler Developmental Outcomes Descriptives

\begin{tabular}{lcccc}
\hline Outcome & \multicolumn{5}{c}{ Score } \\
& Minimum & Maximum & Mean & SD \\
\hline PARCA-R Cognitive & 0 & 34 & 28.22 & 3.91 \\
\hline PARCA-R Language & 4 & 124 & 82.26 & 29.89 \\
\hline BITSEA Problem & 0 & 32 & 7.87 & 5.02 \\
\hline BITSEA Competence & 8 & 22 & 18.90 & 2.29 \\
\hline
\end{tabular}


FAMILY LEAVE AND DEVELOPMENTAL OUTCOMES

Table 3.

Results of Multiple Regression Analysis of Maternal Employment on Toddler Language Outcomes

\begin{tabular}{lcccc}
\hline & $\beta$ & $\mathrm{SE}$ & $p$ & adj. $\mathrm{R}^{2}$ \\
\hline Overall model & & 27.92 & $<.01$ & 0.24 \\
\hline $\begin{array}{l}\text { Maternal } \\
\text { Employment }\end{array}$ & 7.73 & 3.41 & .02 & \\
\hline Infant Age & 2.26 & 0.32 & $<.01$ & \\
\hline Infant Sex & 14.47 & 2.75 & $<.01$ & \\
\hline Site & 16.79 & 4.27 & $<.01$ & \\
\hline Gestational Age & 1.16 & 0.88 & 0.19 & \\
\hline Household Income & $<.01$ & $<.01$ & $<.01$ & \\
\hline Maternal Education & 0.16 & 0.70 & 0.82 & \\
\hline
\end{tabular}

Table 4.

Results of Multiple Regression Analysis of Paid Leave on Toddler Language Outcomes

\begin{tabular}{lcccc} 
& $\beta$ & $\mathrm{SE}$ & $p$ & adj. $\mathrm{R}^{2}$ \\
\hline Overall model & & 26.78 & $<0.01$ & 0.19 \\
\hline Paid Leave & 8.96 & 3.43 & 0.01 & \\
\hline Infant Age & 2.37 & 0.36 & $<0.01$ & \\
\hline Infant Sex & 10.01 & 3.06 & $<0.01$ \\
\hline Site & 15.94 & 5.14 & $<0.01$ \\
\hline Gestational Age & 1.42 & 1.01 & 0.15 & \\
\hline Household Income & 0.00 & 0.00 & 0.00 & \\
\hline Maternal Education & -0.34 & 0.83 & 0.69 &
\end{tabular}


FAMILY LEAVE AND DEVELOPMENTAL OUTCOMES

Table 5.

Results of Multiple Regression Analysis of Paid Leave on Toddler Behavioral Problem Scores

\begin{tabular}{lcccc}
\hline & $\beta$ & $\mathrm{SE}$ & $p$ & adj. $\mathrm{R}^{2}$ \\
\hline Overall Model & & 4.91 & $<0.01$ & 0.06 \\
\hline Paid Leave & -9.56 & 4.07 & 0.02 & \\
\hline Maternal Education & -0.48 & 0.22 & 0.04 & \\
\hline Paid Leave*Maternal Education & 0.63 & 0.26 & 0.02 \\
\hline Infant Age & 0.02 & 0.07 & 0.77 \\
\hline Infant Sex & -1.10 & 0.56 & 0.05 \\
\hline Site & -1.18 & 0.94 & 0.21 \\
\hline Gestational Age & 0.03 & 0.18 & 0.85 & \\
\hline Household Income & $<0.01$ & $<0.01$ & $<0.01$ & \\
\hline
\end{tabular}


FAMILY LEAVE AND DEVELOPMENTAL OUTCOMES

\section{Figures}
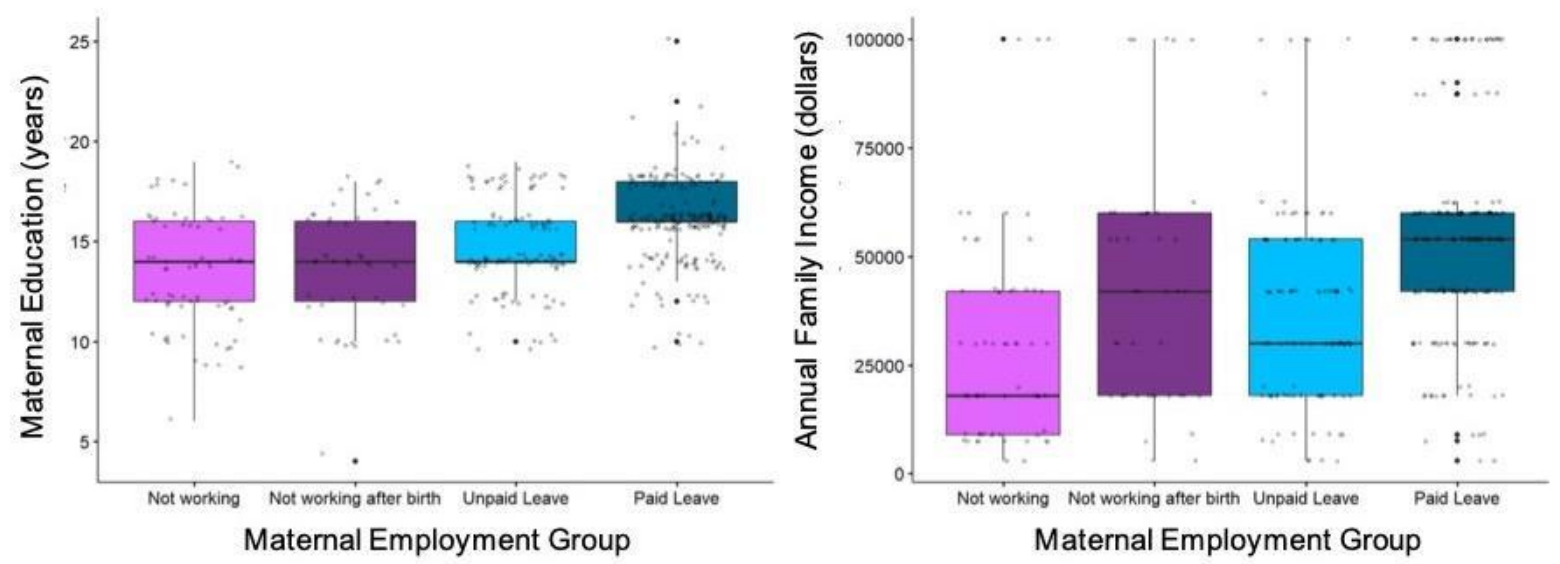

Figure 1. Socioeconomic variability across maternal employment status 
FAMILY LEAVE AND DEVELOPMENTAL OUTCOMES

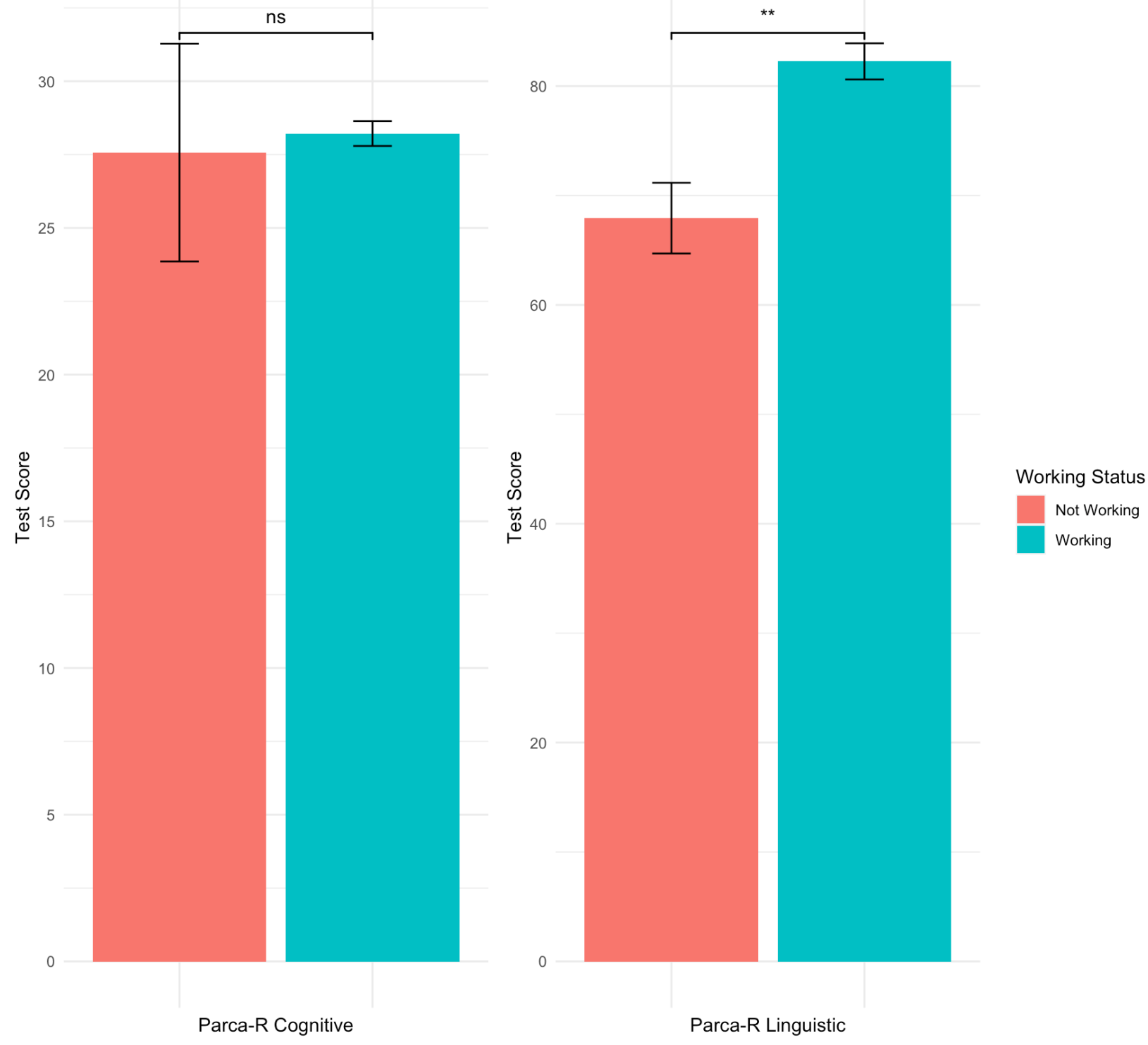

Figure 2. Significant differences in working vs not working found in PARCA-R linguistic but not cognitive scores $(* * p=0.02)$ 
FAMILY LEAVE AND DEVELOPMENTAL OUTCOMES

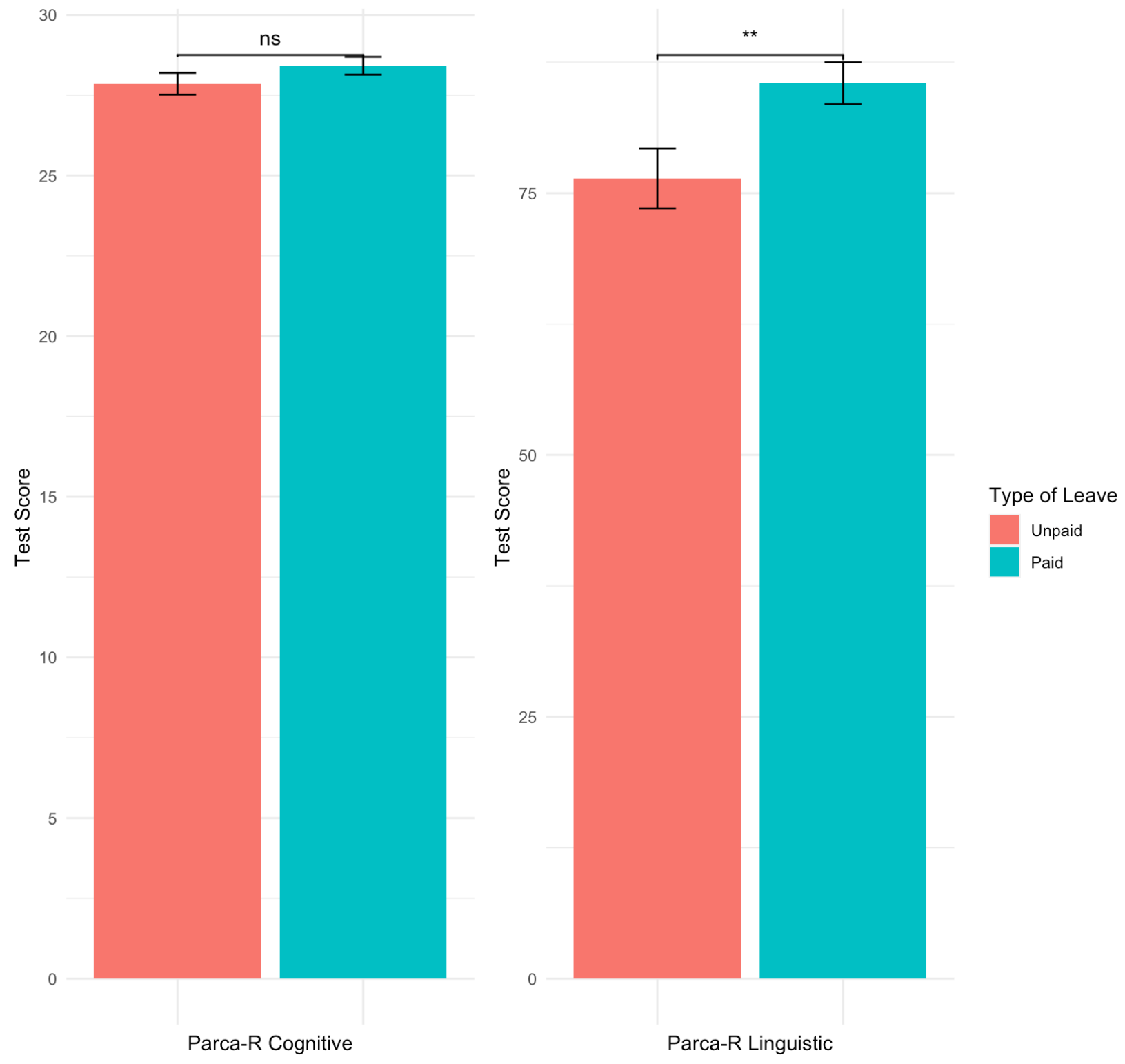

Figure 3. Significant differences in paid vs. unpaid leave found in PARCA-R linguistic but not cognitive scores $(* * p<0.01)$ 
FAMILY LEAVE AND DEVELOPMENTAL OUTCOMES

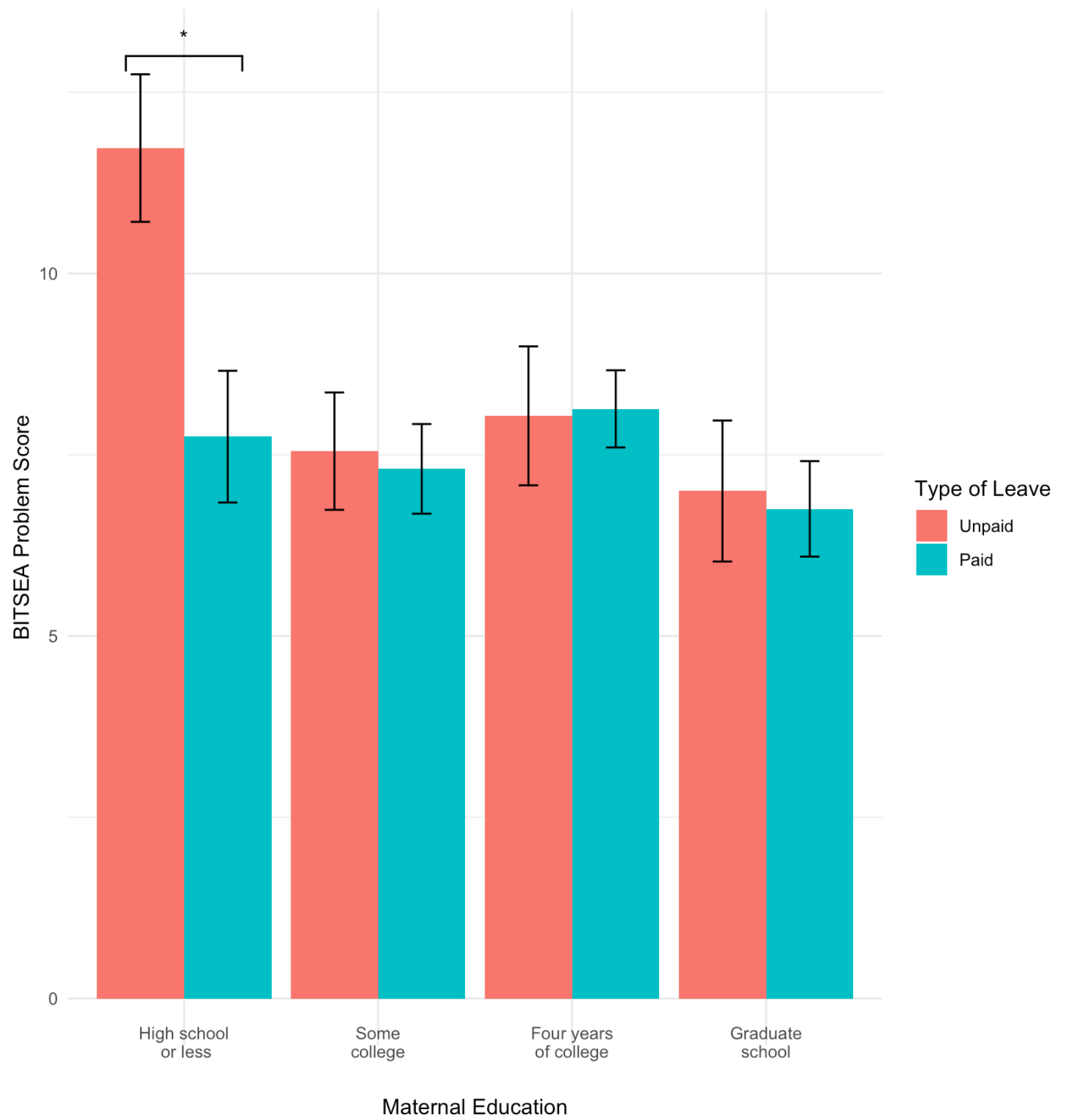

Figure 4. Johnson-Neyman analysis suggests that paid leave is significantly related to lower BITSEA problem scores, but only for mothers with lower levels of education. Variables are categorized here for visualization purposes only. 
FAMILY LEAVE AND DEVELOPMENTAL OUTCOMES

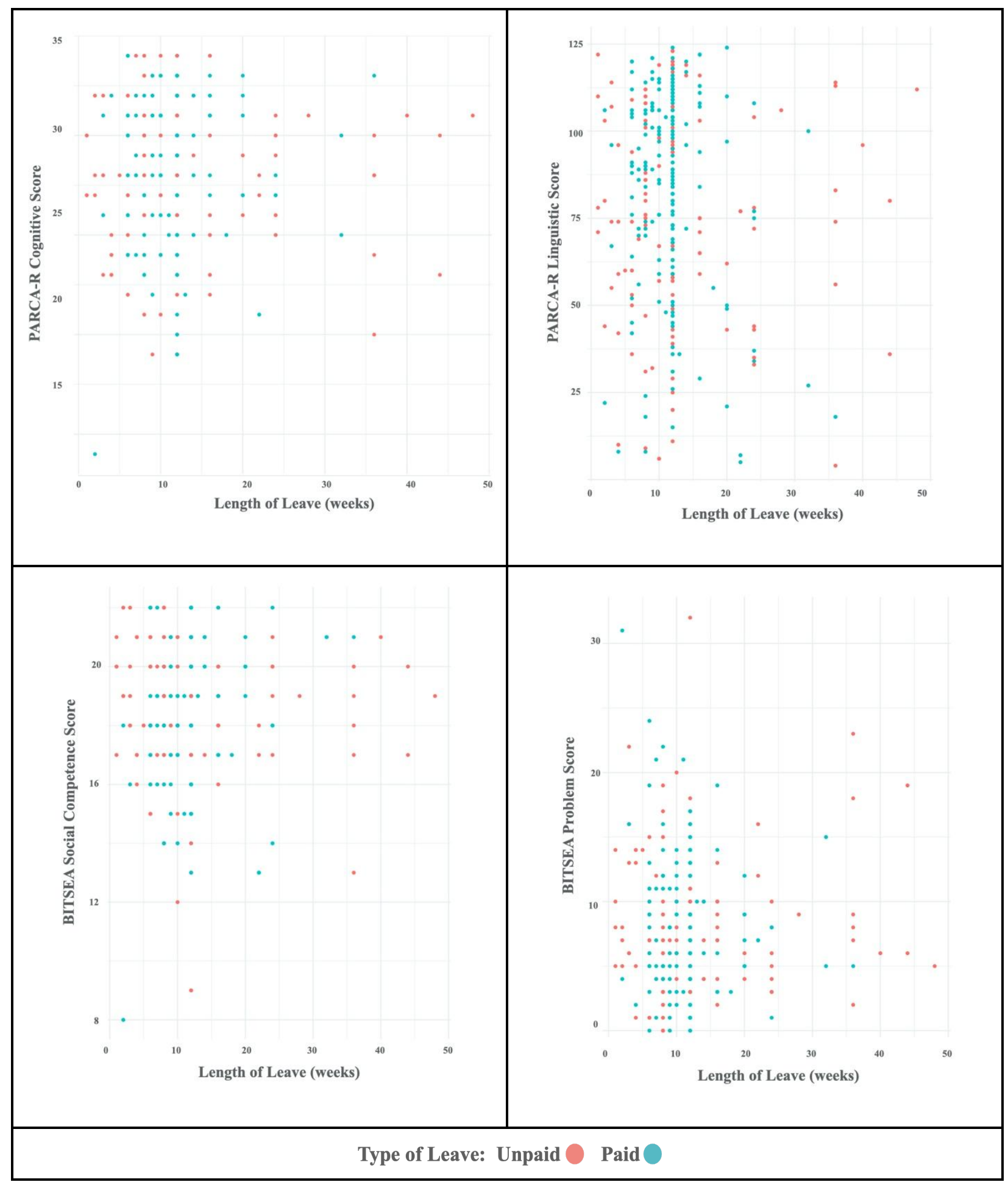

Figure 5. There were no associations between the length of maternity leave and toddler developmental outcomes. 